\title{
Neuropsychological Aspects of Aging and Driving for Inclusive Automotive Interior Design
}

\author{
Susana C. F. Fernandes ${ }^{1,2,3}$, Yamisel Chong Espino ${ }^{4,5}$ \\ ${ }^{1}$ Associated Laboratory for Energy, Transports, and Aeronautics INEGI/LAETA, University of Porto, Porto, Portugal \\ ${ }^{2}$ Department of Mechanical Engineering, School of Engineering, Polytechnic of Porto, Porto, Portugal \\ ${ }^{3} \mathrm{~N} 2 \mathrm{i}$, Polytechnic Institute of Maia, Maia, Portugal \\ ${ }^{4}$ University Institute of Maia (ISMAI), Maia, Portugal \\ ${ }^{5}$ Unit for Research in Human Development and Psychology_UNIDEP, University Institute of Maia, Maia, Portugal \\ Email: scf@isep.ipp.pt, yespino@ismai.pt
}

How to cite this paper: Fernandes, S.C.F. and Chong, Y. (2021) Neuropsychological Aspects of Aging and Driving for Inclusive Automotive Interior Design. Journal of Transportation Technologies, 11, 390-403. https://doi.org/10.4236/jtts.2021.113025

Received: June 2, 2021

Accepted: July 3, 2021

Published: July 6, 2021

Copyright $\odot 2021$ by author(s) and Scientific Research Publishing Inc. This work is licensed under the Creative Commons Attribution International License (CC BY 4.0).

http://creativecommons.org/licenses/by/4.0/ (c) (i) Open Access

\begin{abstract}
As people grow older, their cognitive functions undergo changes which may result in uncomfortable driving situations and even increase the risk of accidents. This research aims to understand the neuropsychological aspects of healthy aging and their possible relationship in changes in motor performance or ability. The research methodology is descriptive and includes a collection of basic studies in the scope of neuroscience, driving tasks, and older driver behavior. The final analysis points to certain changes in the functioning of the cerebral cortex and its connections as being responsible for poor performance in some basic driving tasks, but which can be compensated for by means of adapted mechanisms in motor vehicles. This study may contribute as a methodological tool, to the automobile design process, for the selection of Advanced Driver Assistance Systems (ADAS) or other emerging technologies which can compensate cognitive changes, improve safety, comfort and inclusion of older drivers in the future of automobile interior design. We conclude that in normal aging, people may present some cognitive deficits especially linked to the frontal and parietal lobe, which interfere with the necessary driving skills albeit not with the dangerous ones and can be compensated by technological solutions. The main innovation of this article is related to the bibliographical compilation and critical analysis in terms of identifying the neuropsychological aspects of normal human aging and car driving and its relationship with possible contributions from vehicular technology, as well its consider future trends in automotive interior design that should be analysed with caution in order to users inclusion.
\end{abstract}




\section{Keywords}

Aging, Cognition, Elderly Drivers, Car Driving Difficulties, Automotive Interior Design

\section{Introduction}

\section{The Neuropsychology of aging and its effects on the driving experience}

The median age of the global population is increasing rapidly, with $25 \%$ of the total population predicted to be over the age of 65 by 2060 [1] [2]. The proportion of vehicles registered to older drivers has increased consistently in recent years and is expected to continue as a trend for a long time to come, while the percentage of vehicles registered to younger drivers has decreased. People aged 65 and older are predicted to be four times more likely to purchase a new vehicle than those under the age of 25 [3] [4], so older drivers represent a target market audience to be considered. However, it also becomes a concern if cars do not meet the needs of the elderly. Older people can expect a longer and healthier life than previous generations, with more activity, mobility, and longer valid driving licenses [5] [6], but longevity brings cognitive changes that can concern both older drivers and other road users regarding their safety [7] [8] [9]. Several studies suggest that the elderly have greater limitations in safe driving tasks [10] [11] [12], often related to cognitive flexibility, visual perception, selective attention [13], and divided attention [14] [15] [16]. The driving task requires the ability to receive and process sensory information and make proper, timely judgments and responses [17].

In normal aging, besides the obvious physical changes, there are general cognitive declines which take place that are critical for interacting with the environment. Some studies point out reduced visual attention [18] [19] [20], slower decision-making capacity, and a general decline in the ability to deal with complex situations [21] [22] [23] [24]. On the other hand, there is also evidence for the existence of different types of compensatory cognitive processes in older drivers [18], known as "self-regulation in driving" [25]. Self-regulation is generally described as the process of modifying or adjusting driving patterns of someone who is driving less or intentionally avoiding driving situations considered to be challenging, typically in response to self-awareness that, for some reason, their driving skills have declined [26] [27]. Self-regulation is made after an assessment of abilities has been carried out, giving rise to behavioral adaptations that will be made depending on the driver's confidence in complex situations that take into account risk, fatigue, and mental workload [9] [27]-[32]. Self-regulation of driving takes into account individual characteristics, including experience, age, gender, personality traits, attitudes, and motivations [33] [34] [35] [36].

\section{The Brain and Car Driving}


In the case of age-related changes in cognitive processes, neuroscientists identify certain brain areas as being primarily responsible. Dysfunction in the frontal lobe is often highlighted, a change that affects the white matter, particularly at the level of the frontal commissures in the corpus callosum and the white matter that connects the frontal lobe with other posterior areas, especially in the right hemisphere. At the cognitive level, the speed of response is a very important factor, and in older adults, we observe an increase in reaction time. In all complex tasks, such as the act of driving, a rapid exchange of information is necessary between the different parts of the brain, not only between cerebral cortical areas but also with other subcortical areas, because it may be necessary to make a decision, inhibit, organize and to control stimuli, among other tasks [37] [38]. Similarly, in the elderly, the frontal dopaminergic pathway may be altered [39] [40] [41] [42] and reduced metabolism in the anterior and middle cingulate cortex, and the left insula, may contribute to decreased information processing speed and explain the slower behavior in older drivers [43] [44] [45].

Spatial abilities develop from childhood to adulthood and then change with aging [46]. Related to this ability, the medial temporal lobe also contributes to non-verbal cognitive tasks, for example in the processing of input or retrieval of information in spatial memory and in the memory of object location and in the treatment of working memory and episodic memory [47].

In the act of driving, these cognitive skills associated with spatial navigation, spatial memory and the ability to maintain spatial information of one's own body when in motion, are very important. We know that the caudate nucleus, part of the hippocampus, para-hippocampus and certain cells of the entorhinal cortex are involved in this processing. Some studies [48] [49] indicate a more noticeable decline of these areas in older people, which could explain why the elderly reveal better orientation in familiar places rather than with less well-known places.

When we select stimuli to analyze, we also suppress others we consider irrelevant. This so-called capacity for appropriate selection may decrease during the normal aging process. In cognitive processing, the simultaneous activation of different brain areas is a natural and common fact. Inhibiting and/or synchronizing the responses of these areas takes a certain amount of time, which may be even greater in the case of the elderly as there is a tendency to activate, in addition to the specific areas commonly used in less aged brains, other contralateral areas [50]. An example of this is observed in the act of driving when areas of the right parietal lobe are activated to resolve conflict resolution and spatial attention tasks.

[51] shows that older, healthy adults have a tendency to pay attention to visual stimuli located on the left hemispace. According to [52], this tendency is associated with greater activity in the right brain hemisphere and is also natural in young adults.

Some authors [53] reinforce these ideas of changes on cognitive processes rather than on motor problems generally associated with driving in the elderly by 
explaining that aging changes in executive performance may be associated with hypoactivation of the anterior insula, inferior frontal operculum, and the presupplementary motor area, all of which are important areas for cognitive organization and the control of subsequent body movements.

Some authors defend the idea that the elderly, in general, tend to be careful people who do not make quick decisions, not because of the fact that they have a problem in the speed of cognitive processing, but because they have a self-perception that in complex situations, it is necessary to divide their attention so that their responses become more elaborate and have the confidence to emit an adequate behavior [54]. Within this scope, it is suggested that certain driving behaviors should be perceived based on other possible problems, such as visual processing abilities, and not as a cognitive problem [11] [12].

In contrast to the changes that occur in the frontal lobe, on the other end of the brain, in the occipital lobe, there appears to be no major morphological or functional changes associated with normal aging that can affect driving [55].

While it is true that cognitive changes are normal in old age, it is also true that other factors can influence the development of these changes. For example, it has been proven that morphological brain changes can vary depending on gender, motor skills, cardiovascular pathologies, cognitive reserve, and/or literacy levels [56].

Most of the literature is focused on a specific driving task, and vehicle driving requires multiple functions which, in turn, involve different brain areas, all of them interconnected. The theme of this study is relevant because it attempts to associate the difficulties of driving a car with the cognitive factors related with aging, in order to shed light on a possible design proposal adapted to cognitive difficulties.

\section{Interior car design adapted to the cognitive needs of the elderly}

Cognitive or thinking skills are essential for safe driving. Such skills allow drivers not only to obtain important information about the driving environment but also to make operational decisions and necessary strategic tactics [57]. While there is wide variability among the elderly, some cognitive skills are more likely to decline with age than others.

To mitigate further difficulties in navigation and loss of position or orientation difficulties, the car interior should provide integrated GPS (Global Positioning Systems). GPS must have clear use and accurate voice support, large text, a high-resolution screen and minimal bells and whistles. It must guarantee driver safety and others road users' safety. Despite few studies, we believe that the future developments of BirdsEye maps technologies will benefit drivers in general, allowing them to view landmarks, from an aerial view, extremely realistic, to make longer trips without getting lost. It can provide satellite imagery maps that provide true representations of surroundings with high-resolution colour imagery (BirdsEye Satellite Imagery maps), high-quality USGS and NRC raster maps that offer a real-life view of terrain and points of interest (BirdsEye TOPO Raster maps) and high-quality raster maps with terrain contours and points of 
interest (BirdsEye Select Raster maps) [58].

Information display interfaces such as "Dashboard" and "Central Console": Radio, GPS, Telephone, Audio and others not only incorporate a lot of information but also require more mental effort and memory and as such, can cause driver distraction when used [59] [60] [61] [62]. If we consider that the differences in cognitive and perceptual abilities between the young and the elderly have implications for in-vehicle tasks, then we can expect older drivers to experience greater difficulties in these operations [63] [64]. In fact, this scenario will increase cognitive demand, mainly due to the way the devices need to be operated [64], as they require an excessive amount of steps for completion; the steps to reaching a particular function are different each time, forcing drivers to search their system and; each function requires a different action from the driver (e.g.: adjusting the temperature of the indoor temperature that is controlled mechanically by sliding knobs, while redirection requires single taps). Too much detail and visual information contained along the interior dashboard surfaces of the vehicle, as well as a high number of devices with incorporated technologies, are a source of distraction as they increase visual and cognitive stimuli, thereby creating mental confusion and increasing the time required for decision making. This can result in more unsafe driving and increase the risk of accidents [57] [65] [66], especially since the driver has to divide attention between road events and the information systems in the vehicle.

The human brain responds to and processes stimuli presented on the left side better, so it is coherent to suggest that relevant driving equipment and/or devices should be positioned on this side of the vehicle's interior, while those that could be distracting should be located on the driver's right.

There are several factors that cause driver distraction from traffic signs, pedestrian movement, and successive lane-changing maneuvers: from road and traffic circumstances to pedestrian movement, to onboard distraction from electrical devices and the multiple tasks of driving. As such, Adaptative Cruise Control (ACC), Active Blind Spot Assist (ABSA), Pre-safe brake, Lane Departure Prevention system (LDP) or Lane Keeping Assistance, Pedestrian Detection, Attention Assist System and Traffic Sign Recognition System provide significant assistance to driving since the elderly require more time to react to stimuli, as for example visual stimuli such as the color changes commonly found in road signage and traffic lights, etc. [58] [67] [68].

Today, despite the studies showing potential cognitive difficulties related to driving, especially among older drivers, the fact is that driver assistance technologies coupled with inclusive design could raise driving longevity. Technological advancements have been significantly present in the automotive industry but vehicle manufacturers should be aware of the need for human adaptation to these technologies, which should be as simple and effective as possible, in order to effectively become driver-friendly (to all ages) technologies. User expectations for the design of automotive interior interfaces are that they are easy to learn, 
memorable, efficient, error-tolerant, and meet the functional purpose for which they were developed.

The future of the automobile will bring opportunities for smart surfaces innovation, for reducing the technology footprint, simplifying manufacturing, reducing user experience giving customers a more intuitive, tangible and unique way to control experience, creating beautifully engineered ergonomic 3D user interfaces, soft and flexible systems. Despite probably becoming the sector, there are roadblocks to smart surfaces innovation that must be predicted with caution by the automobile sector, such as the form factor and user experience that are extremely relevant for the inclusion of drivers with previous memories and experiences.

Another emerging automotive trend is integrating technologies in areas with thermoformable polymer sensors, unlocking smart surfaces with smarter materials, replacing traditional sensors with functional materials (seamless and 3D surfaces).

The desire creation of a more tactile future and gestural commands will bring new interaction modes that must be analysed with caution. Currently, part of the user's interaction with the interior car devices is done in a tactile way, which is less intuitive and simple, enhancing discretion and requiring greater tactile control skills for older drivers. More tests should be run on the tactility-or the lack of it-in automotive interiors.

A human-centred design-driven approach to technology (tangible innovation in smart surfaces for automotive interior) is a research challenge for the next years, where senior drivers may represent an implementation obstacle in moving towards gestural commands and new interaction modes.

It is important to establish an evidence-based framework that clearly predicts risks so that drivers can continue driving for as long as possible, and thereby increase their independence and quality of life, reducing the risk of accidents to the drivers themselves and other road users [57] [69] [70] [71].

This work tries to contribute to the knowledge of the biological bases of the driving behavior of elderly adults. Understanding the changes in the brains of the elderly is important to develop compensatory technological mechanisms.

\section{Results}

With regards to cognition, our analysis provides a more accurate picture of the needs of the elderly in terms of automobile driving tasks (see Figure 1). Insofar as healthy aging is concerned, individuals seem to know how to drive, although they are qualitatively different from young adults.

Aging produces cognitive changes that affect motor activity especially at the level of the frontal lobe in the cerebral cortex, among other areas. In sixteen of the major cognitive activity-dependent driving difficulties in elderly drivers identified in the literature, $46 \%$ of these difficulties require processing in the frontal lobe, the main control center for these complex activities, while $27 \%$ are dependent on the activity in the parietal cortex. The remaining percentage is distributed 


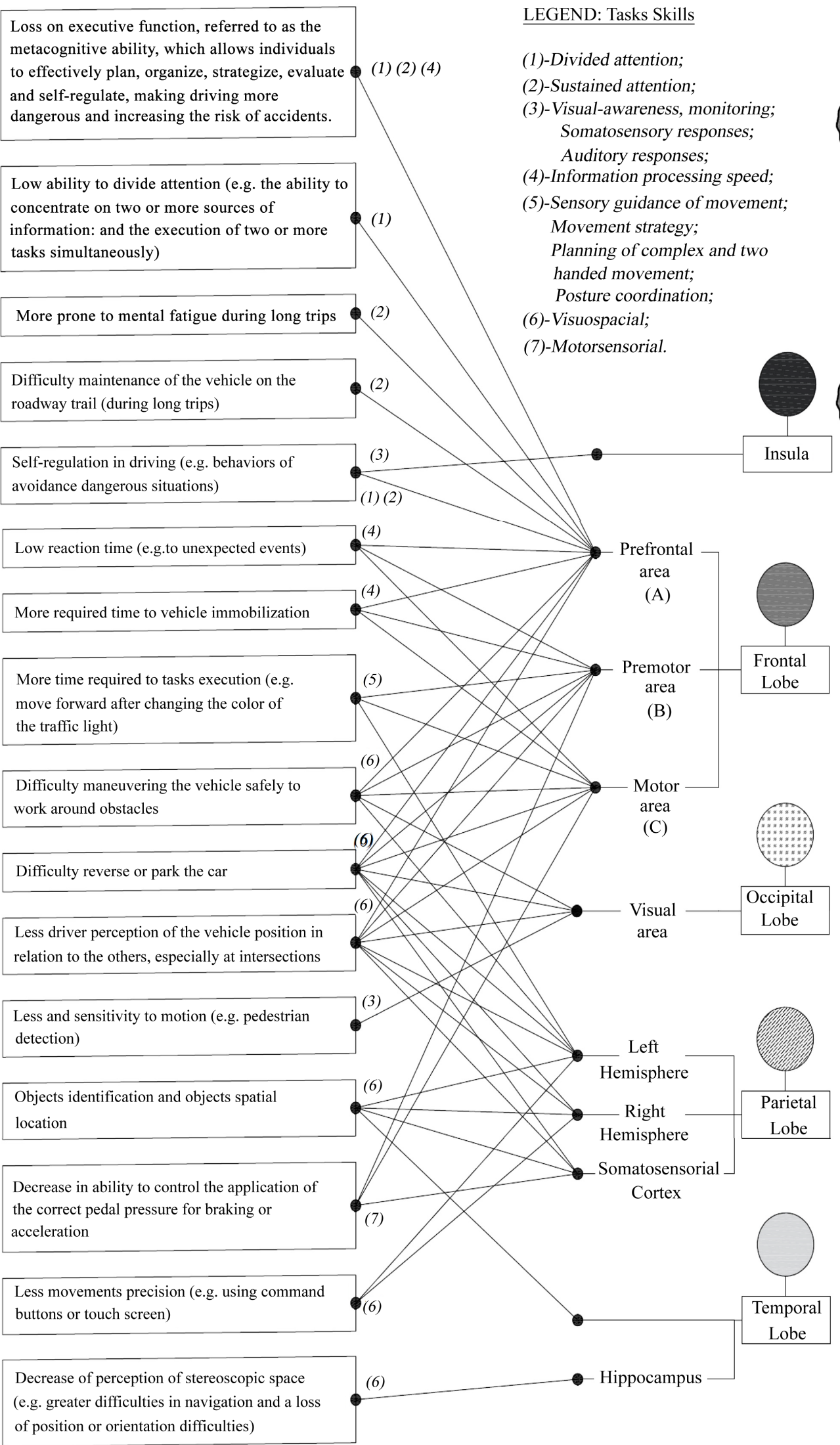

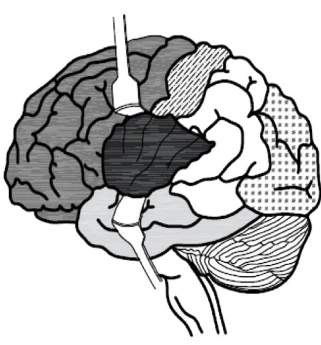

Lateral View

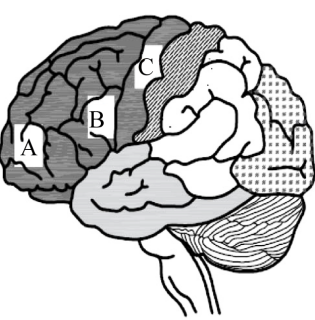

Lateral View

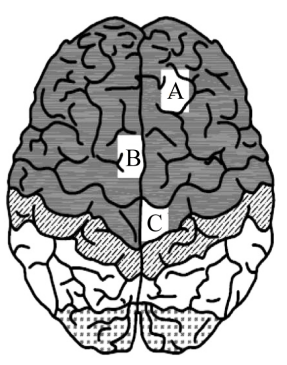

Superior View

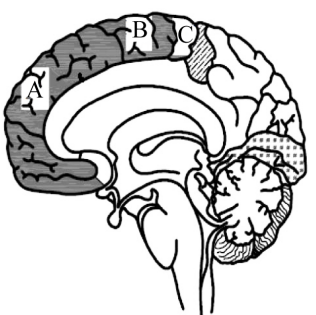

Sagittal View

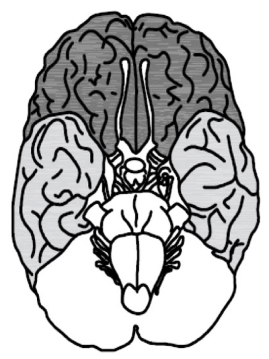

Inferior View

Figure 1. Seniors main automobile driving difficulties and corresponding cortex functional areas. 
in different areas which are also important for navigation, including the hippocampus in the temporal lobe (see Figure 2). In addition to these areas, the need for the proper functioning of the neuronal networks that connect the various brain regions should also be taken into account.

It is interesting to note that most research done in the area of aging and driving talks about visual, motor (physical) and attention problems. In this work, we present a range of cognitive changes associated with healthy aging that can impede comfortable driving.

In normal aging, frontal and parietal lobe changes are well known. The results presented are in line with the literature and add an even more detailed breakdown of the problems presented in the act of driving.

\section{Discussion and Conclusions}

The driving experience makes vehicle operations become relatively more automatic. At the motor level, we can speak of a procedural memory that causes the release of brain areas linked to voluntary attentional processes, which are more active at the early stages of learning to drive. Age can bring this advantage; however, areas of the brain that are important for the driving process, present alterations that need to be compensated with internal strategies, that is, generated by the individual himself through the activation of other brain areas, or by external strategies, found in the vehicle itself such as the use of technology adapted to the needs of the older driver.

While the aging process has different effects on the elderly, several studies show that aging results in fewer cognitive abilities that are considered potentially unsafe for driving a car. However, as shown in Figure 1, some of the tasks considered the most demanding for elderly drivers and that requires several areas of the cerebral cortex (e.g. the task of parking) cannot necessarily be classified as the most dangerous for drivers and other road users. As the literature shows, tasks that require greater integration of brain areas are not necessarily more dangerous because when they are perceived as dangerous or challenging, older drivers tend to avoid them with self-regulatory behaviors. The most demanding tasks identified in older individuals (applying multiple parts of the cerebral cortex) can be mitigated with appropriate technological resources that can benefit
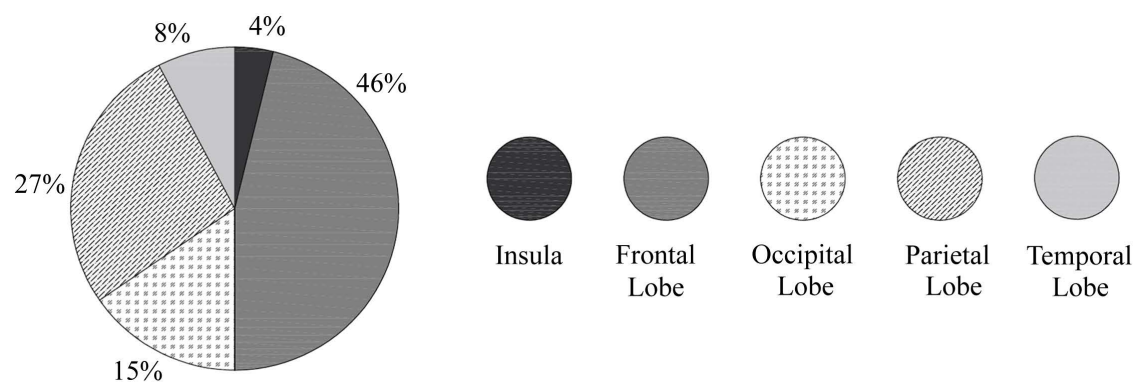

Figure 2. Percentage of areas of the cerebral cortex activated during automobile driving tasks considered to more difficult in elderly drivers and that are cognition dependent. 
older drivers with a better driving experience. Adapting technologies to user needs is a process that must be carried out through the careful analysis of individuals' capabilities. This will not only increase comfort but also driver safety and the safety of other road users. Driving is much more than a motor skill and from a cognitive perspective, some of the deficits in normal aging that are very important for good driving have been pointed out. It is our perspective that, in the future, vehicles especially aimed at older drivers may offer tools that will at least allow for calculations based on spatial dimensions according to vehicle size and/or other external forces. They must provide technology that makes it possible to analyze the movement of other elements in the environment, assisting in decision making, inhibiting or slowing down driver behavior, planning driving options, assisting in programming one's own body movement, increasing/enhancing the ability to perceive visual and auditory stimuli so as to avoid irrelevant driving stimuli, as well as providing a comfortable environment that increases attentional capacity (for example, with more technological options to be made available in the driver's left space). All of these options can be taken into account in addition to the features already found in today's vehicles, such as navigation/location assistance. Future technologies should be designed to help older drivers compensate for their cognitive deficits, making driving safer and more comfortable.

Future research topics could be focused on the quality of life and satisfaction of the elderly with the implementation of adapted technologies, in addition to analyzing the differences in automobile driving difficulties.

\section{Conflicts of Interest}

The authors declare no conflicts of interest regarding the publication of this paper.

\section{References}

[1] SRA Trafikverket (2014) Trender i transportsystemet, Trafikverkets omvärldsanalys 2014. [Online] Technical Report, Trafikverket, 115.

https://www.trafikverket.se/contentassets/45209ee3d0794131a9afc17ce67ab6aa/tren der_i_transportsystemet_2014_2014-115_final.pdf

[2] United Nations, Department of Economic and Social Affairs, Population Division (2015) World Population Prospects: The 2015 Revision, Key Findings and Advance Tables. Working Paper No. ESA/P/WP.241. https://population.un.org/wpp/publications/files/key_findings_wpp_2015.pdf

[3] Kurz, C., Li, G. and Vine, D. (2016) The Young and the Carless? The Demographics of New Vehicle Purchases, FEDS Notes. Board of Governors of the Federal Reserve System, Washington DC. https://doi.org/10.17016/2380-7172.1798

[4] Phelan, M. (2014) New Technology Makes Driving Safer for Seniors. https://www.usatoday.com/story/money/cars/2014/05/08/new-technology-makes-d riving-safer-for-seniors/8883243

[5] Kahvedzic, A. (2013) International Re-Licensing Models of Older Drivers. https://www.rcpi.ie/wp-content/uploads/2016/02/4_International-Re-Licensing-Mo 
dels-of-Older-Drivers-1.pdf

[6] Musselwhite, C. and Haddad, H. (2008) An Exploration into the Travel Needs of Older Drivers. The 4th International Conference on Traffic and Transport Psychology, Washington DC, 31 August-4 September 2008.

[7] Deng, H., Chen, W., Kuang, S. and Zhang, T. (2017) Distinct Aging Effects on Motion Repulsion and Surround Suppression in Humans. Frontiers in Aging Neuroscience, 9, 363. https://doi.org/10.3389/fnagi.2017.00363

[8] Kowalski, K., Love, J., Tuokko, H., Macdonald, S., Hultsch, D. and Strauss, E. (2012) The Influence of Cognitive Impairment with No Dementia on Driving Restriction and Cessation in Older Adults. Accident Analysis and Prevention, 49, 308-315. https://doi.org/10.1016/j.aap.2011.11.011

[9] Mardh, S. (2016) Identifying Factors for Traffic Safety Support in Older Drivers. Transportation Research Part F, 18, 118-126. https://doi.org/10.1016/j.trf.2016.01.010

[10] Fernandes, S.C.F., Esteves, J. L., Uva, P. and Simoes, R. (2016) Aspetos Psicológicos e Cognitivos do envelhecimento: A vivência sénior e a condução automóvel. Symposium Conducted at the Meeting of Aveiro University, Aveiro, 22-23 July 2016.

[11] Leversen, J., Hopkins, B. and Sigmundsson, H. (2013) Ageing and Driving: Examining the Effects of Visual Processing Demands. Transportation Research Part F, 17, 1-4. https://doi.org/10.1016/j.trf.2012.11.003

[12] Stinchcombe, A. and Gagnon, S. (2013) Aging and Driving in a Complex World: Exploring Age Differences in Attentional Demand While Driving. Transportation Research Part F, 17, 125-133. https://doi.org/10.1016/j.trf.2012.11.002

[13] Anstey, K.J. and Wood, J. (2011) Chronological Age and Age-Related Cognitive Deficits Are Associated with an Increase in Multiple Types of Driving Errors in Late Life. Neuropsychology, 25, 613-621. https://doi.org/10.1037/a0023835

[14] Ebnali, M., Ahmadnezhad, P., Shateri, A., Mazloumi, A., Ebnali Heidari, M. and Nazeri, A.R. (2016) The Effects of Cognitively Demanding Dual-Task Driving Condition on Elderly People's Driving Performance; Real Driving Monitoring. Accident, Analysis and Prevention, 94, 198-206. https://doi.org/10.1016/j.aap.2016.05.016

[15] Eby, D., Molnar, L. and Kartje, P. (2008) Maintaining Safe Mobility in an Ageing Society. CRC Press, Boca Raton. https://doi.org/10.1201/9781420064544

[16] Shaheen, S. and Niemeier, D. (2001) Integrating Vehicle Design and Human Factors: Minimizing Elderly Driving Constraints. Institute of Transportation Studies, University of California, Berkeley. https://doi.org/10.1016/S0968-090X(99)00027-3

[17] Yale, S.H., Hansotia, P., Knapp, D. and Ehrfurth, J. (2003) Neurologic Conditions: Assessing Medical Fitness to Drive. Clinical Medicine and Research, 1, 177-188. https://doi.org/10.3121/cmr.1.3.177

[18] Andrews, E.C. and Westerman, S.J. (2012) Age Differences in Simulated Driving Performance: Compensatory Processes. Accident Analysis and Prevention, 45, 660668. https://doi.org/10.1016/j.aap.2011.09.047

[19] Molnar, L.J., Eby, D.W., Zhang, L., Zanier, N., St. Louis, R.M. and Kostyniuk, L.P. (2015) Self-Regulation of Driving by Older Adults: A Synthesis of the Literature and Framework for Future Research. [online] Technical Report, AAA Foundation for Traffic Safety, Washington DC. https://aaafoundation.org/self-regulation-driving-older-adults

[20] Rao, P., Muñoz, B., Turano, K., Munro, C. and West, S.K. (2013) The Decline in 
Attentional Visual Fields over Time among Older Participants in the Salisbury Eye Evaluation Driving Study. Investigative Ophthalmology and Visual Science, 54, 18391844. https://doi.org/10.1167/iovs.11-8874

[21] Bernhoft, I.M. (1990) Elderly Drivers. Results from a Nordic In-Depth Study on Elderly Car Drivers. Proceedings of the Third European Workshop on Recent Developments in Road Safety Research, Linköping, 26-27 April 1990, VTI Report No. 366A.

[22] Cobb, R.W. (1998) Are Elderly Drivers a Road Hazard? Problem Definition and Political Impact. Journal of Aging Studies, 12, 411-427. https://doi.org/10.1016/S0890-4065(98)90027-5

[23] Dehlin, O., Hagberg, B., Rundgren, Å., Samuelsson, G. and Sjöbeck, B. (2000) Gerontologi-Åldrandet i ett biologiskt, psykologiskt och socialt perspektiv, Falköping, Natur och Kultur, Stockholm.

[24] Mathias, J.L. and Lucas, L.K. (2009) Cognitive Predictors of Unsafe Driving in Older Drivers: A Meta-Analysis. International Psychogeriatrics, 21, 637-653. https://doi.org/10.1017/S1041610209009119

[25] Bergen, G., West, B.A., Luo, F., Bird, D.C., Freund, K., Fortinsky, R.H. and Staplin, L. (2017) How Do Older Adult Drivers Self-Regulate? Characteristics of Self-Regulation Classes Defined by Latent Class Analysis. Journal of Safety Research, 61, 205-210. https://doi.org/10.1016/j.jsr.2017.01.002

[26] Devlin, A. and McGillivray, J. (2016) Self-Regulatory Driving Behaviours amongst Older Drivers According to Cognitive Status. Transportation Research Part F: Traffic Psychology and Behaviour, 39, 1-9. https://doi.org/10.1016/j.trf.2016.02.001

[27] Molnar, L.J., Eby, D.W., Charlton, J.L., Langford, J., Koppel, S., Marshall, S. and Man-Son-Hing, M. (2013) Reprint of Driving Avoidance by Older Adults: Is It Always Self-Regulation? Accident Analysis and Prevention, 61, 272-280. https://doi.org/10.1016/j.aap.2013.07.004

[28] Charlton, J., Oxley, J., Fildes, B., Oxley, P., Newstead, S., Koppel, S. and O'Hare, M. (2006) Characteristics of Older Drivers Who Adopt Self-Regulatory Driving Behaviours. Transportation Research Part F: Traffic Psychology and Behaviour, 9, 363-373. https://doi.org/10.1016/j.trf.2006.06.006

[29] Hassan, H., King, M. and Watt, K. (2015) The Perspectives of Older Drivers on the Impact of Feedback on Their Driving Behaviours: A Qualitative Study. Transportation Research Part F: Traffic Psychology and Behaviour, 28, 25-39. https://doi.org/10.1016/j.trf.2014.11.003

[30] Rudin-Brown, C. and Jamson, S. (2013) Behavioural Adaptation and Road Safety: Theory, Evidence and Action. CRC Press, Boca Raton.

https://doi.org/10.1201/b14931

[31] Sullivan, K.A., Smith, S.S., Horswill, M.S. and Lurie-Beck, J.K. (2011) “Older Adults" Safety Perceptions of Driving Situations: Toward a New Driving Self-Regulation Scale. Accident Analysis and Prevention, 43, 1003-1009.

https://doi.org/10.1016/j.aap.2010.11.031

[32] Wong, I., Smith, S. and Sullivan, K. (2012) The Relationship between Cognitive Ability, Insight and Self-Regulatory Behaviors: Findings from the Older Driver Population. Accident Analysis and Prevention, 49, 316-321. https://doi.org/10.1016/j.aap.2012.05.031

[33] Baumann, M. and Krems, J.F. (2007) Situation Awareness and Driving: A Cognitive Model. In: Cacciabue, P.C., Ed., Modelling Driver Behaviour in Automotive Environments. Critical Issues in Driver Interactions with Intelligent Transport Systems, 
Springer, London, 253-265. https://doi.org/10.1007/978-1-84628-618-6_14

[34] Eby, D. and Molnar, L. (2012) The University of Michigan Transportation Research Institute Ann Arbor, Michigan 48109-2150 U.S.A., Report No. UMTRI-2012-5.

[35] Machin, M.A. and Sankey, K.S. (2008) Relationships between Young Drivers Personality Characteristics, Risk Perceptions, and Driving Behavior. Accident Analysis \& Prevention, 40, 541-547. https://doi.org/10.1016/j.aap.2007.08.010

[36] Summala, H. (2007). Towards Understanding Motivational and Emotional Factors in Driver Behaviour: Comfort through Satisficing. In: Cacciabue, P.C., Ed., Modelling Driver Behaviour in Automotive Environments. Critical Issues in Driver Interactions with Intelligent Transport Systems, Springer, London, 189-207.

https://doi.org/10.1007/978-1-84628-618-6_11

[37] Talwar, N.A., Churchill, N.W., Hird, M.A., Pshonyak, I., Fischer, C.E., Graham, S.J. and Schweizer, T.A. (2020) Effects of Mild Cognitive Impairment on Brain Function during Distracted Driving. Alzheimer's \& Dementia, 16, e043494. https://doi.org/10.1002/alz.043494

[38] Ledger, S., Bennett J., Chekaluk, E. and Batchelor, J. (2019) Cognitive Function and Driving: Important for Young and Old Alike. Transportation Research Part F: Traffic Psychology and Behaviour, 60, 262-273. https://doi.org/10.1016/j.trf.2018.10.024

[39] Goh, J.O., Beason-Held, L.L., An, Y., Kraut, M.A. and Resnick, S.M. (2013) Frontal Function and Executive Processing in Older Adults: Process and Region Specific Age-Related Longitudinal Functional Changes. Neuroimage, 69, 43-50.

https://doi.org/10.1016/j.neuroimage.2012.12.026

[40] Nyberg, L., Salami, A., Andersson, M., Eriksson, J., Kalpouzos, G., Kauppi, K., Nilsson, L., et al. (2010) Longitudinal Evidence for Diminished Frontal Cortex Function in Aging. Proceedings of the National Academy of Sciences, 107, 22682-22686. https://doi.org/10.1073/pnas.1012651108

[41] Persson, J., Nyberg, L., Lind, J., Larsson, A., Nilsson, L., Ingvar, M. and Buckner, R. (2006) Structure-Function Correlates of Cognitive Decline in Aging. Cerebral Cortex, 16, 907-915. https://doi.org/10.1093/cercor/bhj036

[42] Van de Vijver, I., Cohen, M. and Ridderinkhof, K.R. (2014) Aging Affects Medial But Not Anterior Frontal Learning-Related Theta Oscillations. Neurobiology of Aging, 35, 692-704. https://doi.org/10.1016/j.neurobiolaging.2013.09.006

[43] Lecouvey, G., Quinette, P., Kalpouzos, G., Guillery-Girard, B., Bejanin, A., Gonneaud, J., Desgranges, B., et al. (2015) Binding in Working Memory and Frontal Lobe in Normal Aging: Is There Any Similarity with Autism. Frontiers in Human Neuroscience, 9, 90. https://doi.org/10.3389/fnhum.2015.00090

[44] Sablotny-Wackershauser, V., Betts, M., Brunnlieb, C., Apostolova, I., Buchert, R., Düzel, E., Gruendler, T. and Vogt, B. (2020) Older Adults Show a Reduced Tendency to Engage in Context-Dependent Decision Biases. Neuropsychologia, 142, Article ID: 107445. https://doi.org/10.1016/j.neuropsychologia.2020.107445

[45] Wai Chiu, P., Zhang, H., Wong, W., Liu, T., Yan Wong, G., Sang Lum, T., Fung Mak, H., et al. (2017) Anterior Cingulate Cortex Exhibits Age-Related Metabolic Changes: Correlation with Behavioral Performance in Attention Task. Poster Presented at the Meeting of Alzheimer's Association, London, 16-20 July 2017.

[46] Shelton, A., Marchette, S. and Furman, A. (2013) Chapter Six-A Mechanistic Approach to Individual Differences in Spatial Learning, Memory, and Navigation. In: Ross, B.H., Ed., Psychology of Learning and Motivation, Academic Press, Vol. 59, Cambridge, 223-259. https://doi.org/10.1016/B978-0-12-407187-2.00006-X

[47] Muffato, V., Meneghetti, C., Di Ruocco, V. and De Beni, R. (2017) When Young 
and Older Adults Learn a Map: The Influence of Individual Visuo-Spatial Factors. Learning and Individual Differences, 53, 114-121. https://doi.org/10.1016/j.lindif.2016.12.002

[48] Armstrong, N., An, Y., Beason-Held, L., Doshi, J., Erus, G., Ferrucci, L., Davatzikos, C. and Resnick, S. (2019) Sex Differences in Brain Aging and Predictors of Neurodegeneration in Cognitively Healthy Older Adults. Neurobiology of Aging, 81, 146-156. https://doi.org/10.1016/j.neurobiolaging.2019.05.020

[49] Duvernoy, H.M., Cattin, F. and Risold, P.-Y. (2013) The Human Hippocampus: Functional Anatomy, Vascularization and Serial Sections with MRI. Fourth Edition, Springer, New York. https://doi.org/10.1007/978-3-642-33603-4_5

[50] Bangen, K., Kaup, A., Mirzakhanian, H., Wierenga, C., Jeste, D. and Eyler, L. (2012) Compensatory Brain Activity during Encoding among Older Adults with Better Recognition Memory for Face-Name Pairs: An Integrative Functional, Structural, and Perfusion Imaging Study. Journal of the International Neuropsychological Society,18, 402-413. https://doi.org/10.1017/S1355617712000197

[51] Schmitz, R. and Peigneux, P. (2011) Age-Related Changes in Visual Pseu-Doneglect. Brain and Cognition, 76, 382-389. https://doi.org/10.1016/j.bandc.2011.04.002

[52] Gawron, N., Lojek, E., Kijanowska-Haładyna, B., Nestorowicz, J., Harasim, A., Pluta, A. and Sobanska, M. (2014) Cognitive Patterns of Normal Elderly Subjects Are Consistent with Frontal Cortico-Subcortical and Fronto-Parietal Neuropsychological Models of Brain Aging. Applied Neuropsychology: Adult, 21, 195-209. https://doi.org/10.1080/09084282.2013.789965

[53] Gruszka, A., Hampshire, A., Barker, R. and Owen, A. (2017) Normal Aging and Parkinson's Disease Are Associated with the Functional Decline of Distinct Frontal-Striatal Circuits. Cortex, 93, 178-192. https://doi.org/10.1016/j.cortex.2017.05.020

[54] Persson, J., Nyberg, L., Lind, J., Larsson, A., Nilsson, L., Ingvar, M. and Buckner, R.L. (2006) Structure-Function Correlates of Cognitive Decline in Aging. Cerebral Cortex, 16, 907-915. https://doi.org/10.1093/cercor/bhj036

[55] Marjanska, M., McCarten, J., Hodges, J., Hemmy, L., Grant, A., Deelchand, D. and Terpstra, M. (2017) Region-Specific Aging of the Human Brain as Evidenced by Neurochemical Profiles Measured Noninvasively in the Posterior Cingulate Cortex and the Occipital Lobe Using $1 \mathrm{H}$ Magnetic Resonance Spectroscopy at 7 T. Neuroscience, 354, 168-177. https://doi.org/10.1016/j.neuroscience.2017.04.035

[56] Ferretti-Rebustini, R., Jacob-Filho, W., Suemoto, C., Farfel, J., Leite, R., Grinberg, L., Nitrini, R., et al. (2015) Factors Associated with Morphometric Brain Changes in Cognitively Normal Aging. Dementia \& Neuropsychologia, 9, 103-109.

https://doi.org/10.1590/1980-57642015DN92000004

[57] Devlin, A., McGillivray, J., Charlton, J., Lowndesc, G. and Etienne, V. (2012) Investigating Driving Behaviour of Older Drivers with Mild Cognitive Impairment Using a Portable Driving Simulator. Accident Analysis and Prevention, 49, 300-307. https://doi.org/10.1016/j.aap.2012.02.022

[58] Fernandes, S.C.F., Esteves, J.L. and Simoes, R. (2017) Characteristics and Human Factors of Older Drivers: Improvement Opportunities in Automotive Interior Design. International Journal of Vehicle Design, 74, 167-203. https://doi.org/10.1504/IJVD.2017.086418

[59] Harvey, C. and Stanton, N.A. (2016) Usability Evaluation for In-Vehicle Systems. CRC Press, Boca Raton. https://doi.org/10.1504/IJVD.2017.086418

[60] Kumar, P. and Verma, M. (2011) Designing Next-Generation Automotive Center 
Consoles. In EE Times Design. http://eetimes.com/design

[61] Pickering, C.A., Bumnham, K.J. and Richardson, M.J. (2007) A Review of Automotive Human Machine Interface Technologies and Techniques to Reduce Driver Distraction. 2007 2nd Institution of Engineering and Technology International Conference on System Safety, London, 22-24 October 2007, 223-228. https://doi.org/10.1049/cp:20070468

[62] Wege, C.A. and Trent, W.V. (2013) Distraction and Inattention Prevention by Combining Behaviour-Based Safety with Advanced Driver Assistance Systems. IET Digital Library, 215-237. https://doi.org/10.1049/PBSP009E_ch11

[63] Caruso, G., Camere, S. and Bordegoni, M. (2016) System Based on Abstract Prototyping and Motion Capture to Support Car Interior Design. Computer-Aided Design and Applications, 13, 228-235. https://doi.org/10.1080/16864360.2015.1084194

[64] Kim, S., Hong, J.H., Li, K.A., Forlizzi, J. and Dey, A.K. (2012) Route Guidance Modality for Elder Driver Navigation. In: Kay, J., Lukowicz, P., Tokuda, H., Olivier, P. and Krüger, A., Eds., Pervasive Computing. Pervasive 2012, Lecture Notes in Computer Science, Vol. 7319, Springer, Heidelberg, 179-196.

https://doi.org/10.1007/978-3-642-31205-2_12

[65] Daigneault, G., Joly, P. and Frigon, J. (2002) Executive Functions in the Evaluation of Accident Risk of Older Drivers. Journal of Clinical and Experimental Neuropsychology, 24, 221-238. https://doi.org/10.1076/jcen.24.2.221.993

[66] Schieber, F. (2003). Human Factors and Ageing: Identifying and Compensation for Age-Related Deficits in Sensory and Cognitive Function. In: Charness, N. and Schaie, K.W., Eds., Impact of Technology on Successful Ageing, Springer Publishing Company, New York, 42-84.

[67] Caird, J., Chisholm, S., Edwards, C. and Creaser, J. (2007) The Effect of Yellow Light Onset Time on Older and Younger Drivers' Perception Response Time (PRT) and Intersection Behavior. Transportation Research Part F: Traffic Psychology and Behaviour, 10, 383-396. https://doi.org/10.1016/j.trf.2007.03.002

[68] Cantin, V., Blouin, J., Simoneau, M. and Teasdale, N. (2004) Driving in a Simulator and Lower Limb Movement Variability in Elderly Persons: Can We Infer Something about Pedal Errors. Advances in Transportation Studies, 12, 39-46.

[69] Molnar, F., Patel, A., Marshall, S., Man-Son-Hing, M. and Wilson, K. (2006) Clinical Utility of Office-Based Cognitive Predictors of Fitness to Drive in Persons with Dementia: A Systematic Review. Journal of the American Geriatrics Society, 54, 18091824. https://doi.org/10.1111/j.1532-5415.2006.00967.x

[70] Pachana, N.A., Jetten, J., Gustafsson, L. and Liddle, J. (2016) To Be Or Not to Be (an Older Driver): Social Identity Theory and Driving Cessation in Later Life. Journal Aging and Society, 37, 1597-1608. https://doi.org/10.1017/S0144686X16000507

[71] Tiraboschi, P., Salmon, D.P., Hansen, L.A., Hofstetter, R.C., Thal, L.J. and Corey-Bloom, J. (2006) What Best Differentiates Lewy Body from Alzheimer's Disease in Early Stage Dementia? Brain, 129, 729-735. https://doi.org/10.1093/brain/awh725 